\title{
Miíase em região submandibular direita: relato de caso
}

\author{
Myiasis in the right submandibular region: case report \\ Miasis em la región submandibular derecha: reporte de un caso
}

Beatriz Nogueira dos Santos ORCID: https://orcid.org/0000-0003-1748-9167 Centro Universitário Cesmac, Brasil

E-mail: beatriznogueira44@ hotmsil.com

Lucas Leverson Lisboa da Costa ORCID: https://orcid.org/0000-0001-9545-5128 Centro Universitário Cesmac, Brasil E-mail: lucasleverson@gmail.com

Alice Christinne de Alencar Lemos ORCID: https://orcid.org/0000-0003-4919-9244 Centro Universitário Cesmac, Brasil E-mail: lemos020@gmail.com

Amanda Marinho Chaves Costa ORCID: https://orcid.org/0000-0002-6566-4890 Centro Universitário Cesmac, Brasil

E-mail: amandamccosta@outlook.com

Analícia Costa Soares

ORCID: https://orcid.org/0000-0002-4157-1323 Centro Universitário Cesmac, Brasil E-mail: analiciacsoares@gmail.com

Letícia Sandes de Albuquerque Silva ORCID: https://orcid.org/0000-0002-8814-4716 Centro Universitário Cesmac, Brasil

E-mail: leticiasandes1998@outlook.com

Maria Júlia Ventura de Albuquerque ORCID: https://orcid.org/0000-0001-5247-197X Centro Universitário Cesmac, Brasil

E-mail: majualbuquerque@outlook.com

Rudson da Silva Nogueira

ORCID: https://orcid.org/0000-0003-4107-5407

Centro Universitário Cesmac, Brasil

E-mail: rudson_lira@hotmail.com

Darllon Manuel Borges de Souza

ORCID: https://orcid.org/0000-0002-9858- 6921 Centro Universitário Tiradentes, Brasil

E-mail: darllonmanuelsouzada@ hotmail.com

Lucya Giselle Costa Moreira

ORCID: https://orcid.org/0000-0002-3658-8163

Centro Universitário Tiradentes, Brasil

E-mail: lucya_giselle@hotmail.com

Lucas Fortes Cavalcanti de Macedo

ORCID: https://orcid.org/0000-0002-8380-6442

Centro Universitário Cesmac, Brasil

E-mail: lucas.macedo@cesmac.edu.br

\begin{abstract}
Resumo
Introdução: A miíase é uma condição patológica caracterizada pela infestação de larvas dípteras em tecidos vivos ou cavidades necróticas, essas larvas se desenvolvem como parasitas sendo alimentadas pelos tecidos do hospedeiro. Tal afecção pode ser classificada em primária, que consiste no desenvolvimento das larvas a partir do tecido vivo (biófago), ou secundária, que é caracterizada por seu desenvolvimento a partir do tecido morto (necrófagos). Objetivo: relatar um caso de míase submandibular em região direita, tratada com ivermectina posteriormente à terapia cirúrgica. Relato de caso: Paciente do gênero masculino, 46 anos, compareceu ao Hospital Geral do Estado com queixa de lesão em região submandibular. Ao exame clínico e de imagem foi possível confirmar o diagnóstico de miíase. Em seguidao o paciente foi conduzido ao centro cirúrgico, onde foi realizado a remoção mecânica das larvas, seguida de desinfecção da lesão e prescrição medicamentosa. A lesão respondeu bem ao tratamento com ivermectina $150 \mu \mathrm{g} / \mathrm{kg}$, administrada por via oral, em dose única. Conclusão: Com isso, foi observado que a remoção de todas as
\end{abstract}


larvas associada à terapia antibiótica, consiste em um bom tratamento para paciente com miíase em região oral e maxilofacial.

Palavras-chave: Miíase; Parasitologia; Medicina bucal.

\begin{abstract}
Introduction: Myiasis is a pathological condition characterized by the infestation of dipterous larvae in living tissues or necrotic cavities these larvae develop as parasites being fed by the host's tissues. This condition can be classified as primary, which consists of the development of larvae from living tissue (biophage), or secondary, which is characterized by its development from dead tissue (necrophages). Objective: To report a case of submandibular myiasis in the right region, treated with ivermectin after surgical therapy. Case report: A 46-year-old male patient attended the State General Hospital complaining of a lesion in the submandibular region. Clinical and imaging examination confirmed the diagnosis of myiasis. Afterwards, the patient was taken to the operating room, where the mechanical removal of the larvae was performed, followed by disinfection of the lesion and medication prescription. The lesion responded well to treatment with ivermectin $150 \mu \mathrm{g} / \mathrm{kg}$, administered orally, in a single dose. Conclusion: Thus, it was observed that the removal of all larvae associated with antibiotic therapy is a good treatment for patients with myiasis in the oral and maxillofacial region.
\end{abstract}

Keywords: Myiasis; Parasitology; Oral medicine.

\title{
Resumen
}

Introducción: La miasis es una condición patológica caracterizada por la infestación de larvas de dípteros em tejidos vivos o cavidades necróticas, estas larvas se desarrollan como parásitos siendo alimentados por los tejidos del huésped. Esta condición se puede clasificar en primaria, que consiste en el desarrollo de larvas a partir de tejido vivo (biofago), o secundaria, que se caracteriza por su desarrollo a partir de tejido muerto (necrófagos). Objetivo: reportar un caso de miasis submandibular en región derecha, tratado con ivermectina después de la terapia quirúrgica. Reporte de un caso: Varón de 46 años que acude al Hospital General del Estado por lesión en región submandibular. El examen clínico y de imagen confirmó el diagnóstico de miasis. Posteriormente, el paciente fue trasladado al quirófano, donde se realizó la remoción mecânica de las larvas, seguido de la desinfección de la lesión y prescripción de medicamentos. La lesión respondió bien al tratamiento con ivermectina $150 \mu \mathrm{g} / \mathrm{kg}$, administrada por vía oral, en una sola dosis. Conclusión: Por lo tanto, se observó que la eliminación de todas las larvas associadas com la terapia con antibióticos es un buen tratamiento para los pacientes con miasis en la región oral y maxilofacial.

Palabras clave: Miasis; Parasitología; Medicina oral.

\section{Introdução}

Miíase é uma condição patológica onde há infestação em tecidos vivos ou cavidades necróticas por larvas dípteras, que se desenvolvem como parasitas, sendo alimentadas por tecido vivo ou morto do hospedeiro. Pode ser classificada como miíase primária, quando as larvas se desenvolvem a partir de tecidos vivos (biófagos), e miíase secundária, quando as larvas se alimentam de tecidos mortos para o seu desenvolvimento (necrófagos) (Martins et al., 2012; Theotonio et al., 2017).

Há uma predominância pelo sexo masculino, devido à negligência em relação à higiene pessoal e atividades realizadas ao ar livre. Sendo diagnosticada clinicamente, observa-se que as regiões tropicais e subtropicais têm uma maior incidência à afecção por miíase, em razão de suas condições climáticas favoráveis (Henrique et al., 2020; Pereira Júnior et al., 2019).

Em vista disso, a infestação de vermes vivos em região maxilofacial é uma condição excruciante, que normalmente afeta indivíduos debilitados, com problemas mentais e com falta de coordenação psicomotora, além disso, alguns fatores predisponentes para miíase nessa região incluem baixo nível socioeconômico e idade avançada, que por vezes interfere na capacidade de suprir suas necessidades de higienização. Os locais mais comumente afetados pela miíase em região de cabeça e pescoço são as orelhas, olhos, cavidade oral, nariz, seios paranasais e linfonofos (Lauand et al., 2020; Pereira Júnior et al., 2019).

Diante disso, pode-se afirmar que essa doença parasitária varia desde quadros benignos até quadros graves com presença de mialgia, febre, odor e desconforto, podendo resultar em óbito. Na região de cabeça e pescoço essa afecção pode estar ou não associada a neoplasias malignas, e dependendo da severidade de destruição tecidual pode ocorrer a perda de visão ou audição do paciente. (Lucena et al., 2020; Marquez et al., 2007). 
Dessa forma, torna-se necessário um tratamento eficaz para o manejo da miíase. Por não haver um protocolo terapêutico padrão para essa condição, diferentes medidas são tomadas para um melhor prognóstico. Geralmente, opta-se pela remoção mecânica das larvas, desbridamento do tecido necrosado e irrigação da ferida, sendo ou não necessário uma antibioticoterapia. A ivernectina oral vem sendo indicada por alguns autores, visto que a ação desse macrolídeo propicia a eliminação das larvas. A finalização com curativo compressivo diminui o oxigênio para os vermes e torna mais fácil a sua remoção (Theotonio et al., 2017; Henrique et al., 2020; Lauand et al., 2020).

Em suma, compete ao cirurgião bucomaxilofacial orientar aos pacientes sobre os cuidados e prevenção dessa patologia, visto que o acometimento em região de cabeça e pescoço pode ter sequelas significativas para o paciente. O presente trabalho tem como objetivo relatar o caso de um paciente com miíase em região submandibular direita, discutindo-se também as formas de apresentação clínica, protocolo cirúrgico e farmacológico.

\section{Metodologia}

Foram realizadas todas as etapas de anamnese, exame físico e de imagem, em seguida foi explicada a abordagem que seria realizada, salientando a necessidade de colaboração do paciente durante os cuidados pós-operatórios. Lamentavelmente, o paciente relatado no caso chegou a óbito devido à outras complicações sistêmicas; por ser morador de rua e não ter relatado acompanhante no local, não foi possível contato com nenhum familiar para que fosse assinado o termo de consentimento livre e esclarecido (TCLE). O trabalho trata-se de um estudo analítico descritivo (Pereira et al., 2018), realizado no Hospital Geral do Estado de Alagoas, registrado e aprovado pelo Comitê de Ética e Pesquisa do Centro Universitário CESMAC.

\section{Resultados e Discussão}

Sendo denominada primeiramente por Frederick William Hope, a palavra "miíase" deriva-se do grego myio (mosca) e ase (doença), esse termo baseia-se na invasão de larvas nos tecidos do corpo ou cavidade de seres vivos, sendo consideradas uma afecção parasitária. Essa doença comumente afeta indivíduos que residem em países subdesenvolvidos e em desenvolvimento. Alguns estudos comprovam com clareza que os países mais acometidos por tal patologia são o Brasil e a Índia. Foi visto que pessoas com necessidades especiais, moradores de rua, ou indivíduos que não conseguem ter uma higienização adequada, são os mais propícios à desenvolverem miíase (Theotonio et al., 2017; Henrique et al., 2020; Passos et al., 2020).

A infestação da larva no hospedeiro se inicia logo depois da penetração, onde uma pequena pápula pode ser formada, dilatando-se e se transformando em um nódulo. O ser humano que possui miíase pode perceber a existência da afecção após o amadurecimento da larva, que mesmo estando localizada em uma região tecidual mais profunda e aderida a eles por meio de seus ganchos, se movimentam e causam desconforto. Além disso, as larvas liberam um esxudato que também pode ser notório. Após a maturação, as larvas migram para fora da ferida e completam seu processo de desenvolvimento quando se tornam novas moscas (Costa et al., 2012; Sampaio, Oliveira, Menezes, 2021).

Além disso, alguns autores afirmam que a miíase desencadeia-se com maior frequência em lugares que possuem clima quente ou regiões tropicais e subtropicais, e geralmente em indivíduos com higiene inadequada, doenças neurológicas e locomotoras, e condições de moradia precárias, possuem uma maior vulnerabilidade para obter essa doença, necessitando de atenção para contribuir com a prevenção dessa afecção e prevenir a infestação de alguma outra infecção secundária, que pode desencadear manifestações clinicas graves (Passos et al., 2020; Antunes et al., 2011; Lauand, 2020; Marquez, Mattos, Nascimento, 2007; Gomez-Puerta et al., 2013). 
Uma vez que a miíase não tenha sido tratada de maneira efetiva, algumas complicações podem se manifestar na região maxilofacial, como a disseminação da infecção para a orbita e lâmina papirácea, ou associações com outras infecções e consequente sepsia, comprometendo a vida do paciente. As áreas mais comumente afetadas por miíase na região de cabeça e pescoço são: ouvidos, olhos, cavidade oral, nariz, seios paranasais, região mastoidea e ferida por traqueostomia. Al-Abidi et al., relataram algumas larvas na área mastóidea direita em um paciente, e as mesmas aos poucos invadiram o cérebro do paciente, trazendo complicações (Avula et al., 2011; Theotonio et al., 2017; Lucena et al., 2020; Thomas et al., 2010).

Apesar de existirem diversas formas de tratamento para miíase relatadas na literatura, ainda não há disponível algum protocolo para utilizarmos na terapia dessa patologia, mas alguns autores defendem que o tratamento da míase consiste na remoção manual de larvas e tecidos necróticos, fazendo o debridamento cirúrgico, com o auxílio de cureta e pinça clínica. Sendo relatada em 1993 como uso seguro em humanos, a ivermectina pode ser utilizada na terapia antibiótica, dependendo da especificidade de cada paciente. Esse macrolídeo, considerado uma droga antiparasitária, deve ser administrado por via oral, em dose única de 150-200 $\mu \mathrm{g} / \mathrm{kg}$. Administrar um agente asfixiante, como éter, clorofórmio, iodofórmio, entre outras substâncias, também pode ser benéfico no momento do procedimento cirúrgico, isso faz com que as larvas que estão localizadas mais profundamente migrem para a superfície, facilitando a remoção desses seres (Antunes et al., 2011; Martins et al., 2012; Theotonio et al., 2017; Pereira Júnior et al., 2019; Marquez, Mattos, Nascimento, 2007; Shinohara et al., 2004; Aoki et al., 2002; Fortuna et al., 2013).

Alguns autores defendem a aplicação de leite de vaca com $20 \%$ de clorofórmio, alegando que a gordura presente no leite causa sufocamento das larvas e posteriormente elas seriam mortas pelo clorofórmio. Outras substâncias também já foram relatadas na literatura, como por exemplo o uso de benzina, infusão de piretro, pulverizações com iodofórmio, água salgada, entre outras soluções. Entretanto, é unânime a escolha do clorofórmio nas feridas infestadas por larvas. Vale ressaltar, que mesmo as larvas estando mortas dentro do tecido do hospedeiro, elas devem ser removidas mecanicamente, pois se apodrecerem podem causar serias complicações (Ayres de Melo et al., 2003).

Ribeiro et al., em 2012 relataram um caso onde foi feita a irrigação com nitrofurazona, um antibiótico responsável por matar bactérias que causam infecções na pele, e foi visto que esse medicamento não demonstrou efetividade para a resolução do caso. Martins et al., relataram em 2012 um caso em que ao invés de se utilizar como agente asfixiante o éter, que é comumente utilizado na terapia cirúrgica do tratamento da miíase, foi aplicada topicamente a solução de eucaliptol (1 -metil, 4isopril ciclohexano, 1-4-óxido), e foi visto que essa solução é menos irritante e inflamável para os tecidos do organismo, demonstrando uma reduzida toxicidade.

\section{Considerações Finais}

Não há na literatura um protocolo terapêutico padrão para o tratamento de miíase oral e maxilofacial, entretanto, usualmente os cirurgiões optam pela remoção mecânica das larvas seguido de terapia antibiótica com ivermectina $\mu \mathrm{g} / \mathrm{kg}$. Se necessário, poderá ser irrigada solução com algum agente asfixiante como o éter na lesão, para as larvas que estiverem presentes nos tecidos mais profundos migrem para a superfície, facilitando sua remoção. Maiores estudes devem ser realizados afim de proporcionar um protocolo terapêutico melhor definido para tratamento de miíase oral e maxilofacial.

\section{Referências}

Antunes, A. A., Santos, T. S., Avelar, R. L., Martins Neto, E. C., Neres, B. M., \& Laureano Filho, J. R. (2011). Oral and maxillofacial myiasis: A case series and literature review. Rev. Oral Surgery, Oral Medicine, Oral Pathology, Oral Radiology and Endodontology. 112(6), 81-85.

Avula, J. K., Avula, H., Arora, N., Manchukonda, U. K., \& Reddy, N. V. (2011). Orofacial myiasis of the gingiva and nasal cavity: A report of two cases and general review. Rev. J. Periodontal. 82(9), 1383-1388. 
Ayres de Melo, R. E. V., Albuquerque Vitor, C. M., Lins e Silva, M. B., Luna, L. A., \& Firmo, A. C. B. (2003). Miíase no lábio superior: Apresentação de caso clínico. Rev. International Journal Of Dentistry. 2(1), 221-226.

Costa, F. S., Bellotti, A., Farah, G. J., \& Camarini, E. T. (2012). Hipertratamento de miŕase decorrente de trauma facial complexo. Rev. Cir. Traumatol. BucoMaxilo-Fac. $12(3)$

Fortuna, T., Costa Neto, W., Rebouças, D. S., Neto, J. M., Marchionni, A. M. T., \& Zerbinati, L. P. S. (2013). Miíase nasal secundária a carcinoma escamocelular: relato de caso. Rev. Brasileira de Cancerologia. 59(4), 559-564.

Freitas Ribeiro, M. T., Sanglard-Oliveira, C. A., Naves, M. D., Ferreira, E. F., Vargas, A. M. D., \& Guimarães Abreu, M. H. N. (2012). Miíase bucal e doença de Alzheimer: relato de caso clínico. Rev. Bras. Geriatr. Gerontol. 15(4), 805-811.

Gomez-Puerta, L. A., Alroy, K. A., Ticona, D. S., Lopex-Urbina, M. T., \& Gonzalez, A. E. (2013). A case of nasal myiasis due to oestrus ovis (díptera: oestridae) in a llama (lama glama). Rev. Bras. Parasitol. 22(4), 608-610.

Henrique, M. M., Henrique, P. R., Paiva, P. M. R., Servato, J. P. S., Faria Júnior, R. B., \& Pinto Júnior, E. R. D. (2020). Miíase furuncular: Relato de caso. Rev. Brazilian Journal Of Development. 6(8), 62684-62691.

Lauand, G. A., Lima, F. G. G. P., Silva, R. P., Santiago, L. R., Dantas, J. B., Silva, C. J., \& Furtado, L. M. (2019). Miíase primária em ferida operatória de fratura de sínfise mandibular: Relato de caso. Rev. Hindawi. 12(1), 5-13.

Lucena, V. R. S., Morais, H. H. A., Souza Júnior, E. F., \& Grempel, R. G. (2020). Tratamento de miíase em trauma facial: Relato de caso. Rev. Portuguesa de Otorrinolaringologia e Cirurgia de Cabeça e Pescoço. 58(1), 37-40.

Marquez, A. T., Mattos, M. S., \& Nascimento, S. B. (2007). Miíases associadas com alguns fatores sócio-econômicos em cinco áreas urbanas do estado do Rio de Janeiro. Rev. Sociedade Brasileira de Medicina Tropical. 40(2), 175-180.

Medeiros Martins, C. A., Freddo, A. L., Gomes, F. V., Maciel Santos, M. E. S., Araldi, C. A., \& Heitz, C. (2012). Oral Myiasis. Rev. The Journal of Craniofacial Surgery. 23(2), 69-71.

Passos, J. B. S., Coelho, L. V., Arruda, J. A. A., Oliveira Silva, L. V., Valle, I. B., Santos, M. S., Figueiredo, E. L., Abreu, L. G., \& Mesquita, R. A. (2020). Oral myiasis: Analysis of cases reported in the English literature from 1990 to 2020. Rev. Spec. Care. Dentist. 11(8), 1-12.

Patussi, C., Lunelli, D. C., Bixofis, R. B., Guebur, M. I., Dissenha, J. L., \& Sassi, L. M. (2014). Myiasis in maxillofacial region: Series of three cases. Ver. Sul Brasileira de Odontologia. 11(3), 303-308.

Pereira Júnior, A. J. A., Pereira, I. P. F., Silva Filho, N. C., \& Reis, C. S. M. (2019). Miíase maxilofacial: Relato de caso. Rev. HU. 45(1), 76-81.

Rodriguez, M. E. L., Aoki, L., Nicolleti, A. G. B., Matayoshi, S., \& Dias Fernandes, J. B. V. (2003). Ivermectina no tratamento de miíase orbitária: Relato de caso. Rev. Arq. Bras. Oftalmol. 66(5), 19-21.

Sampaio, A. T. P., Oliveira, E. S., \& Menezes, M. R. S. (2021). Assistência de enfermagem em miíase humana para pessoas em situação de rua: revisão integrativa da literatura. Rev. JRG de Estudos Acadêmicos. 4(8), 159-172.

Shinohara, E. H., Martini, M. Z., Oliveira Neto, H. G., \& Takahashi, A. (2004). Oral myiasis treated with ivermectin: Case report. Rev. Braz. Dent. J. 15(1), $79-81$.

Theotonio, J. A., Resende, A. F., Louro, R. S., Uzeda, M. J., \& Resende, R. F. (2017). Óbito decorrente de miíase em região maxilofacial: Relato de caso clínico. Rev. Cir. Traumatol. Buco-Maxilo-Fac. 17(4), 27-31.

Thomas, S., Nair, P., Hegde, K., \& Kulkarni, A. (2010). Nasal Myiasis with orbital and palatal complications. Rev. BMJ Case Reports. 10(2), 1-4. 